\title{
RMS-MP3 Classification: A Newly Proposed Digital MP3 Classification in Assessing Skeletal Maturity
}

\author{
Raghavendra M Shetty ${ }^{1}$, Shailja Hanumanta ${ }^{2}$
}

\begin{abstract}
Background: Growth is a crucial inconsistent parameter, which is a primary requisite in diagnosing and planning orthodontic and orthopedic treatment. The use of the epiphyseal development of the middle phalanx of the third finger (MP3) radiograph is advisable instead of hand and wrist radiographs for growth assessment.

Aim: (1) To propose a simple, precise, and reliable classification system of MP3 staging-RMS MP3 classification and (2) to check the reliability of newly proposed RMS-MP3 classification in assessing the skeletal maturity.

Materials and methods: Standardized MP3 digital radiographs of 276 children between 5 years and 13 years of age were included in the study. The epiphysis and diaphysis were measured, and the percentage of epiphysis formed when compared to diaphysis was obtained using our formula. A new classification was designed and proposed. The assessment of the MP3 developmental stages was carried out by all the four investigators (two pedodontists and two nonpedodontists) according to the older classification by Liete et al. and the newly proposed RMS-MP3 classification. Results: Among nonpedodontists, there was $51 \%$ perfect agreement of maturity stages according to old classification and $90 \%$ perfect agreement according to newly proposed classification. Among pedodontists, there was $90 \%$ perfect agreement of maturity stages according to old classification and $99 \%$ perfect agreement according to the newly proposed classification. An estimated $89 \%$ of agreement was seen in RMS-MP3 classification among all the four observers when compared to $38 \%$ of agreement in the old classification.
\end{abstract}

Conclusion: The newly proposed RMS-MP3 classification can be an alternative and perfect aid in assessing growth with accuracy, precision, ease, and an increased reliability.

Keywords: Growth prediction, MP3 classification, RMS-MP3 classification reliability, Skeletal maturity.

International Journal of Clinical Pediatric Dentistry (2019): 10.5005/jp-journals-10005-1632

\section{INTRODUCTION}

Assessment of growth plays a crucial role in treatment planning. Although growth events occur in a reasonably constant sequence, the ages at which they are reached vary considerably among the children. The indicators of the developmental age are, therefore, more informative than the chronological age, particularly for clinical application. ${ }^{1}$ The treatment plan can vary from growth modification by myofunctional appliances in children to orthognathic surgery in adults, depending on growth status.

Todd was the first author who mentioned in 1937 the term "determinant of the maturity," referring to the gradual changes that occur on the growth of the cartilage during the trial of coalition of the epiphysis with the diaphysis. ${ }^{2}$ Years later, Greulich and Pyle called them indicators of maturity and in 1959 they established the norms of skeletal age to value the bone maturation of the complete hand. ${ }^{3}$

Numerous skeletal maturity indicators have been advocated such as cervical vertebra, ${ }^{4,5}$ hand-wrist radiograph, ${ }^{6}$ frontal sinus, ${ }^{7}$ and dental indicators. ${ }^{8}$

Skeletal maturity regarding whether pubertal growth has started, is occurring, or has been completed is commonly determined by a hand-wrist radiograph evaluation, ${ }^{9}$ but it requires additional time and exposure of the patient to additional radiation. ${ }^{10}$ In the current era of radiation awareness, the use of the epiphyseal development of the middle phalanx of the third finger (MP3) radiograph is advisable instead of hand wrist radiographs for growth assessment. ${ }^{11-14}$

The stages of epiphyseal development in MP3 radiograph was originally described by Hagg and Taranger with a conventional
${ }^{1}$ Department of Preventive and Pediatric Dentistry, Gulf Medical University, Ajman, United Arab Emirates

${ }^{2}$ Department of Pedodontics, Government Dental College, Raipur, Chhattisgarh, India

Corresponding Author: Raghavendra M Shetty, Department of Preventive and Pediatric Dentistry, Gulf Medical University, Ajman, United Arab Emirates, Phone: +971 563019421, e-mail: raghavendra77@yahoo.com

How to cite this article: Shetty RM, Hanumanta S. RMS-MP3 Classification: A Newly Proposed Digital MP3 Classification in Assessing Skeletal Maturity. Int J Clin Pediatr Dent 2019;12(4):255-260.

Source of support: Nil

Conflict of interest: None

radiographic film. ${ }^{15}$ Later it was modified by Leite et al. (Table 1). ${ }^{16}$ As there is a paradigm shift from conventional to digital, it is advised to use radiovisuography (RVG) for evaluation of epiphyseal growth of middle phalanx as it offer numerous advantages over conventional radiograph such as low exposure, enhanced image quality, precise measurements, and easy storage for future comparisons.

Digital radiography of the MP3 region is definitely a simple, reliable, cost-effective, and time-saving technique for the assessment of skeletal maturity. ${ }^{17}$ However, the growth analysis done by Leite et al. ${ }^{16}$ using digital radiograph has the major disadvantage being that, it is based on the arbitrary judgement. It was seen many a times that there was confusion in predicting whether epiphysis was more than $75 \%$ or less. Lack of an exact and precise measurement pushed us to formulate the new

o The Author(s). 2019 Open Access This article is distributed under the terms of the Creative Commons Attribution 4.0 International License (https://creativecommons. org/licenses/by-nc/4.0/), which permits unrestricted use, distribution, and non-commercial reproduction in any medium, provided you give appropriate credit to the original author(s) and the source, provide a link to the Creative Commons license, and indicate if changes were made. The Creative Commons Public Domain Dedication waiver (http://creativecommons.org/publicdomain/zero/1.0/) applies to the data made available in this article, unless otherwise stated. 
Table 1: Old classification of MP3 stages $^{16}$

\begin{tabular}{|c|c|}
\hline Stages & Descriptions \\
\hline Stage 1 & $\begin{array}{l}\text { The epiphysis reaches } 3 / 4 \text { of the width of the diaphysis } \\
\text { (E3/4) }\end{array}$ \\
\hline Stage 2 & The epiphysis is as wide as the diaphysis (MP3 F) \\
\hline Stage 3 & $\begin{array}{l}\text { The epiphysis is as wide as the diaphysis and there is a } \\
\text { distinct medial and/or lateral border of the epiphysis } \\
\text { forming a line of demarcation at the right angle to the } \\
\text { distal border (MP3 FG) }\end{array}$ \\
\hline Stage 4 & $\begin{array}{l}\text { The sides of epiphysis have thickened and also cap its } \\
\text { diaphysis forming a sharp edge distally at one or both } \\
\text { sides (MP3 G) }\end{array}$ \\
\hline Stage 5 & Fusion of epiphysis and diaphysis has begun (MP3 H) \\
\hline Stage 6 & Fusion of epiphysis and diaphysis is completed (MP3 I) \\
\hline
\end{tabular}

method of measurement of growth through radiovisuography (RVG) and also to propose a new classification based on the exact measurements that would overcome the drawbacks of arbitrary judgement.

An appropriate classification is one that can consistently reproduce the same result irrespective of the observation made by same or different observer with or without adequate knowledge of it. The aim of the present study was (1) to propose a simple, precise, and reliable classification system (using digital measurements) that can be easily utilized and reproduced whenever required and (2) to check the reliability of newly proposed RMS-MP3 classification in assessing the skeletal maturity.

\section{Materials and Methods}

MP3 radiographs of 276 children between 5 years and 13 years of age who visited the department and required skeletal maturity assessment as part of orthodontic or orthopedic treatment over the period of three years were included in the study. The selection criteria included healthy children with no previous history of injury/ trauma to the hand especially in the third finger. Ethical clearance was obtained prior to commencement of the study, and a written consent was obtained from parents/caregiver prior to radiographic exposure.

\section{Standardization of Radiographs}

The MP3 radiographs were taken using digital radiographic system (Kodak 5100, size\#1 sensor) with a standard radiographic machine (Confident) with the standard exposure parameters (70 kV, $7 \mathrm{~mA}$, 0.08 seconds).

To standardize the radiograph, a plaster block was prepared, which comprised a negative space to accommodate an \#1 size intraoral RVG sensor. The block consisted of vertical and two horizontal lines that help in the guiding position of the area of interest. The subjects were instructed to place the middle phalanx region of the third finger in intersection area of lines (Fig. 1). The radiographic cone was kept perpendicular to area of interest and in light contact with finger and predetermined exposure was done.

\section{Assessment of MP3 Maturity in RVG}

To accurately determine the development of epiphyseal plate, the epiphysis and diaphysis on the digital image were measured using a digital scale present in the RVG software. The width of diaphysis was measured from the maximum convexity of one end to the other by the digital scale as shown in Figure $2(10.2 \mathrm{~mm}$ in the present

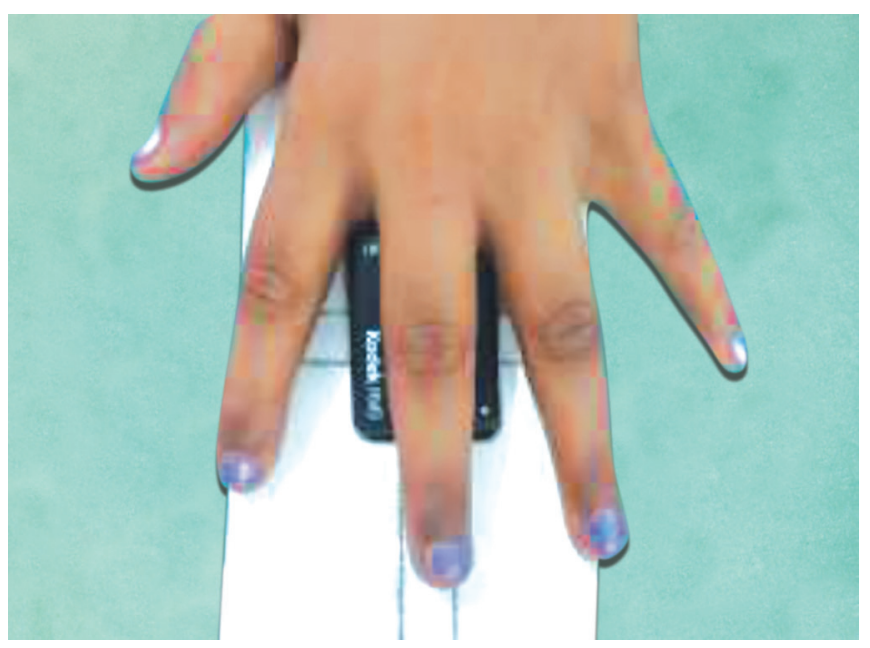

Fig. 1: Third finger position on an RVG sensor

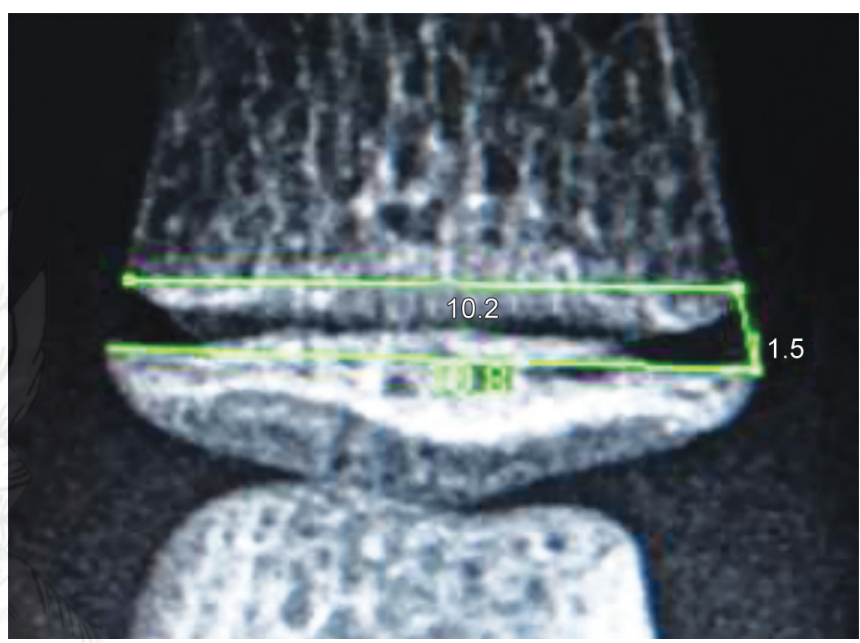

Fig. 2: Measurement of epiphysis and diaphysis using a digital scale in RVG

radiograph). Similarly, the width of the epiphysis was measured from the maximum convexity of one end to the other by the digital scale as shown in Figure 2 (10.8 $\mathrm{mm}$ in the present radiograph). The percentage of epiphysis formed when compared to diaphysis was obtained using the formula:

$$
\frac{\text { Width of epiphysis }}{\text { Width of diaphysis }} \times 100
$$

\section{Newly Proposed Classification: RMS-MP3 Classification}

On the basis of digital measurements, a new classification was designed and proposed based on developmental size and shape of epiphysis. The newly proposed classification was named as "RMSMP3 Classification" and it comprised ten stages (Table 2).

\section{Illustrations to Interpret the Radiographs by RMS-MP3 Classification}

To explain the newly proposed classification, few radiographs have been interpreted and explained as follows.

\section{Scenario 1}

Figure $3 \mathrm{~A}$ shows a radiograph in which epiphysis formation is minimal. The width of epiphysis was $5.7 \mathrm{~mm}$ and the width of 
Table 2: Newly proposed RMS-MP3 classification of MP3 stages

\begin{tabular}{|c|c|}
\hline Stages & Description \\
\hline Stage 1 & No formation or $<50 \%$ of epiphysis is formed \\
\hline Stage 2 & $\begin{array}{l}\text { Width of epiphysis is equal to or }<75 \% \text { of diaphysis } \\
\text { with no widening or blunting }\end{array}$ \\
\hline Stage 3 & $\begin{array}{l}\text { Width of epiphysis is equal to or }<75 \% \text { of diaphysis } \\
\text { with widening or blunting of one or both the ends }\end{array}$ \\
\hline Stage 4 & $\begin{array}{l}\text { Width of epiphysis }>75 \% \text { of diaphysis without } \\
\text { widening or blunting on either of end }\end{array}$ \\
\hline Stage 5 & $\begin{array}{l}\text { Width of epiphysis }>75 \% \text { of diaphysis with widening } \\
\text { or blunting on one or both ends }\end{array}$ \\
\hline Stage 6 & $\begin{array}{l}\text { Equal to width of diaphysis and blunt on both the } \\
\text { ends }\end{array}$ \\
\hline Stage 7 & $\begin{array}{l}\text { Sides of epiphysis have thickened and also caps } \\
\text { diaphysis forming sharp angle }\end{array}$ \\
\hline Stage 8 & Fusion of epiphysis with diaphysis but $<50 \%$ \\
\hline Stage 9 & Fusion of epiphysis with diaphysis but $>50 \%$ \\
\hline Stage 10 & Complete fusion of epiphysis with diaphysis \\
\hline
\end{tabular}

diaphysis was $10.0 \mathrm{~mm}$. So the percentage of epiphysis formed was equal to $57 \%$, as derived using our formula: width of epiphysis $(5.7 \mathrm{~mm}) /$ width of diaphysis $(10.0 \mathrm{~mm}) \times 100$ (Fig. 3B). According to the revised classification, it was categorized as stage 2 .

\section{Scenario 2}

Figure $4 \mathrm{~A}$ shows a radiograph, which by assumption usually falls into stage 1 of Leite et al.'s classification, i.e. 3/4th of the epiphysis formed. But with the digital scale, the width of epiphysis measured was $5.7 \mathrm{~mm}$ and the width of diaphysis was $8.0 \mathrm{~mm}$. So the percentage of epiphysis formation was equal to $71.25 \%(5.7 / 8.0 \times 100)$ (Fig. 4B), which is less than 3/4th, which appreciates the use of digital scale measurements disagreeing the measurement with the assumption and falls into stage 2 of the revised classification.

\section{Scenario 3}

Figure $5 \mathrm{~A}$ shows a radiograph usually categorized as stage 2 of Leite et al.'s classification stating that epiphysis is equal to diaphysis. When measured and calculated, it was $91.75 \%$ (Fig. 5B), which is less than the assumed measurement and is clearly defined in the revised classification as stage 5 .

\section{Scenario 4}

Figure $6 \mathrm{~A}$ shows a radiograph in which fusion of epiphysis with diaphysis has started, which is less than $50 \%$ and is described as stage 8 in the revised classification.

Figure $6 \mathrm{~B}$ shows a radiograph in which fusion of epiphysis with diaphysis which is more than $50 \%$, which is described as stage 9 in the revised classification.

Figure $6 \mathrm{C}$ shows a radiograph in which there is a complete fusion of epiphysis with diaphysis, which is described as stage 10 in the revised classification.

\section{Reliability of the Newly Proposed Classification Folder 1}

The folder consisted of 276 radiographs in the sequential manner according to the identification number without any measurements. These radiographs were used for the assessment of the MP3
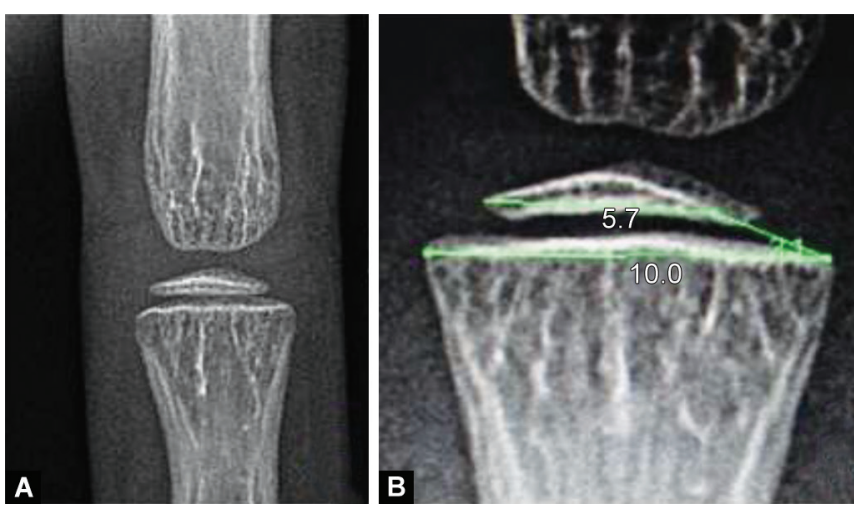

Figs $3 \mathrm{~A}$ and B: Initiation of epiphysis formation. (A) Without measurement; (B) With measurement
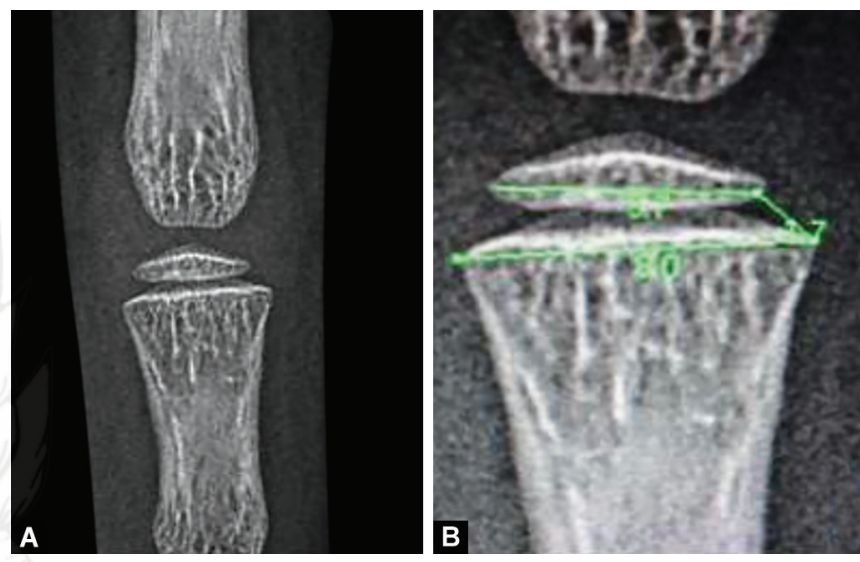

Figs 4A and B: A comparison (stage 1) according to: (A) Old classification; (B) RMS-MP3 classification
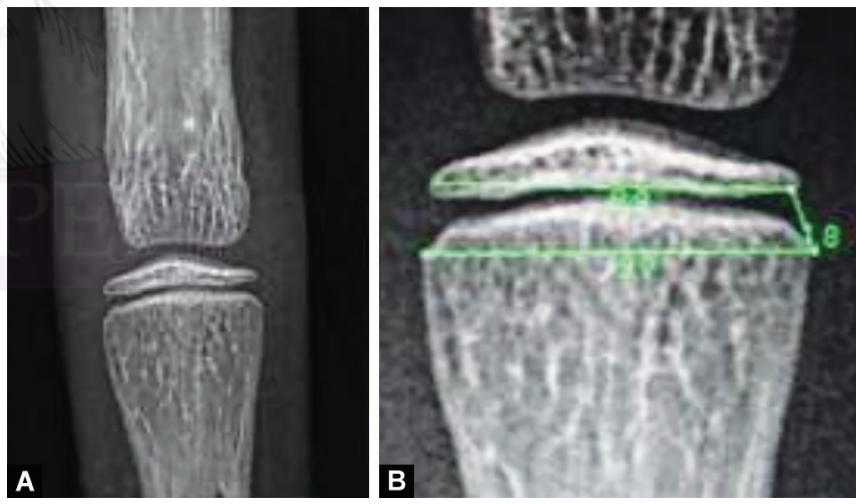

Figs $5 \mathrm{~A}$ and $\mathrm{B}$ : A comparison (stage 2 ) according to: (A) Old classification; (B) RMS-MP3 classification

developmental stages according to the old classification by Leite et al. ${ }^{16}$

\section{Folder 2}

To accurately determine the development of the epiphyseal plate, the epiphysis and diaphysis on the digital image was measured using a digital scale present in the RVG software. The percentage of epiphysis formed when compared to diaphysis was obtained using our formula:

$$
\frac{\text { Width of epiphysis }}{\text { Width of diaphysis }} \times 100
$$



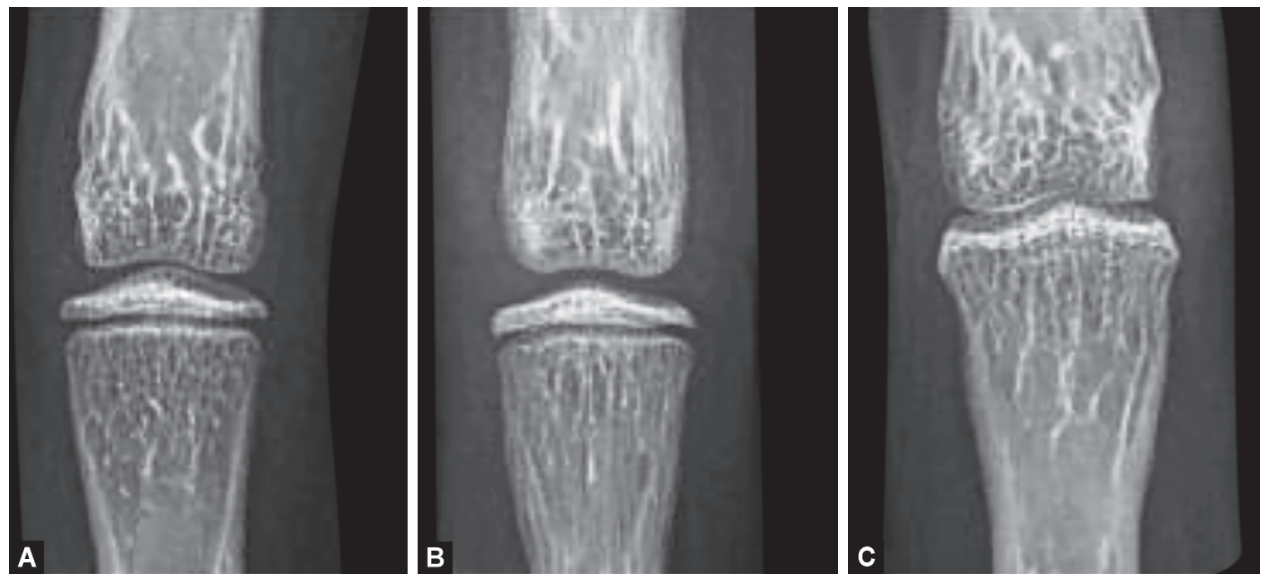

Figs 6 A to C: A radiograph demonstrating: (A) Less than 50\%; (B) More than 50\%; (C) Complete fusion of the epiphysis and diaphysis

Percentages were calculated for all the 276 radiographs and were arranged in the sequential manner according to the identification number similar to the earlier one but with calculated measurements (percentage) written along with the digital radiographs. These radiographs with measurements were used for the assessment of the MP3 developmental stages according to the RMS-MP3 classification.

\section{Assessment of Radiographs}

The study included four investigators to assess the growth through the radiographs. Two among them were pedodontist posing adequate knowledge about MP3 maturity indicator and radiology and two were nonpedodontist (BDS graduates) who did not have adequate knowledge about the MP3 maturity indicator. All the four investigators were briefed about the classifications and a hand out was provided containing both the classifications. The assessment of the MP3 developmental stages was carried out by all the four investigators according to the older classification by Liete et al. and the newly proposed RMS-MP3 classification.

The stages were tabulated, compared, and statistically analyzed by Pearson's Chi-square test using SPSS software (version 17.5) and the statistical significance was tested at the $5 \%$ level.

\section{Results}

The agreement between two pedodontists and two nonpedodontists using the old classification system was tabulated (Table 3). There were 142 (51\%) radiographs, in which nonpedodontists showed perfect agreement, while 226 (82\%) radiographs in which pedodontists showed agreement. The difference in the proportion of agreement between pedodontists and nonpedodontists was highly significant $(p<0.001)$.

Table 3: Agreement within observers using old classification system

\begin{tabular}{|c|c|c|c|c|}
\hline \multirow[b]{2}{*}{ Old classification } & \multicolumn{2}{|c|}{ Observer } & \multicolumn{2}{|c|}{ Significance } \\
\hline & Nonpedodontist & $\overline{\text { Pedodontist }}$ & $\chi^{2}$ & $p$ value \\
\hline No agreement & $134(49 \%)$ & $50(18 \%)$ & 57.522 & $0.0001^{*}$ \\
\hline $\begin{array}{l}\text { Perfect } \\
\text { agreement }\end{array}$ & $142(51 \%)$ & $226(82 \%)$ & & \\
\hline Total samples & 276 & 276 & & \\
\hline
\end{tabular}

*Highly significant
The agreement between pedodontists and nonpedodontists using the RMS-MP3 classification system were tabulated (Table 4). There were 248 (90\%) radiographs in which nonpedodontists showed perfect agreement, while 274 (99\%) radiographs in which pedodontists showed agreement. The difference in the proportion of observers showing agreement in two groups was statistically highly significant.

To compare the classifications, the old classification was categorized into three categories (i.e., stage 1-3 (pre-peak), 4 (peak) and 5-6 (post-peak)). ${ }^{13,17}$ Similarly, the newly proposed RMS-MP3 classification was categorized as 1-6 (pre-peak), 7 (peak), and 8-10 (post-peak) stages (Table 5).

The number of radiographs for which there was agreement between pedodontists and nonpedodontists in the old and new classification system, taking the categories into consideration, were tabulated (Table 6). Accordingly, as per the old classification system, there were only 106 (38\%) radiographs showing perfect agreement between pedodontists and nonpedodontists, while as per RMS-MP3 classification system, there were 246 (89\%) radiographs with perfect agreement between pedodontists and nonpedodontists. The difference in the proportion of agreement between two classification systems was statistically significant.

Table 4: Agreement within observers using the new classification system

\begin{tabular}{|c|c|c|c|c|}
\hline \multirow{2}{*}{$\begin{array}{l}\text { RMS-MP3 } \\
\text { classification }\end{array}$} & \multicolumn{2}{|c|}{ Observer } & \multicolumn{2}{|c|}{ Significance } \\
\hline & Nonpedodontist & Pedodontist & $x^{2}$ & $p$ value \\
\hline No agreement & $28(10 \%)$ & $2(1 \%)$ & 23.452 & $0.0001^{*}$ \\
\hline $\begin{array}{l}\text { Perfect } \\
\text { agreement }\end{array}$ & $248(90 \%)$ & 274 (99\%) & & \\
\hline Total samples & 276 & 276 & & \\
\hline
\end{tabular}

*Highly significant

Table 5: Categorization of the maturational stages of the MP3

\begin{tabular}{lll}
\hline Category & Old classification & RMS-MP3 classification \\
\hline Prepeak & Stages $1-3$ & Stages $1-6$ \\
Peak & Stage 4 & Stage 7 \\
Post-Peak & Stages 5-6 & Stages 8-10 \\
\hline
\end{tabular}


Table 6: Agreement within and between observers for the old and new classification

\begin{tabular}{llrlll}
\hline & \multicolumn{2}{c}{ Classification } & & \multicolumn{2}{c}{ Significance } \\
\cline { 2 - 3 } \cline { 5 - 6 } Agreement & Old & RMS-MP3 & & $\chi^{2}$ & p value \\
\hline No agreement & $170(62 \%)$ & $30(11 \%)$ & & 153.68 & $0.0002^{*}$ \\
Perfect & $106(38 \%)$ & $246(89 \%)$ & & \\
agreement & & & & \\
Total samples & 276 & 276 & & \\
\hline
\end{tabular}

*Significant

\section{Discussion}

The terms of growth and development are used to indicate the series of changes of volume, forms, and weight that suffers the organism from the fecundation until the mature age. ${ }^{18}$ The concept of biological maturity is defined as the successive transformations from conception to the adulthood through time. Bone age and the dental age are the two methods to evaluate maturity. ${ }^{19}$

Owing to the wide individual variation, the chronological age cannot be used in the evaluation of the pubertal growth. ${ }^{20}$ For that reason, it is appealing to determine the biological age. The study of the bone maturation is the surest and reliable method to evaluate the biological age of the individuals and to fix the physiologic maturity. ${ }^{19}$ The maturation stages can have a considerable influence on the diagnosis, the goals of the treatment, the planning, and the eventual result of the orthodontic treatment. ${ }^{13,21}$

The timing of recognition of pubertal growth spurt is important in percept of early orthodontics. It is during this growth phase, the somatic growth rate is at its maximum. Every growth spurt has a definite onset, accelerating phase, peak of the growth spurt, decelerating phase, and end of the growth spurt. The duration of this growth spurt is short in females (around 3-4 years) compared to males, in whom it extends $4-5$ years. The girls have an earlier onset of puberty, whereas in the boys, late onset is seen. The accelerating phase may last for 2 years on average. After 3-4 years of the end of this growth spurt, the active growth ceases. ${ }^{22-24}$

From the clinical point of view in the planning of an orthodontic treatment, we should consider whether the patient has begun the spurt of pubertal growth, whether this is happening in that moment, or whether it has concluded. With the analysis of the stages of maturation of the middle phalanx of the third finger, visualized in an X-ray of $41 \times 31 \mathrm{~mm}$, it is possible to assess the potential growth in orthodontics patients. ${ }^{25}$

MP3 staging given by previous authors ${ }^{15,16}$ are based on assumptions, whereas the newly proposed RMS-MP3 classification is based on the exact measurements of epiphysis and diaphysis growth. Also, the present method fulfilled the principle of ALARA (as low as reasonably achievable), according to which the patient should be subjected to only that amount of radiation that is absolutely necessary for diagnostic purposes. ${ }^{11}$

No staging regarding initial development phase of epiphysis formation has been explained in the older classifications. Also in radiograph the epiphysis formation may be assumed as more than 3/4th, but when accurately measured, it may not be the same or vice versa according to the older classification. In the newer classification, exact measurement and categorization can be done without any confusion. Along with the formation, developmental shape of epiphysis has also been included in system, which provides an added advantage of precise categorization. Among the fusion stages, in classical classification, it is either described as beginning of fusion or completion of fusion, but in newly proposed classification, it has been better categorized according to the extent of the fusion.

The newly proposed RMS-MP3 classification uses the advantage of digitalized technique and also allows to measure the growth indicators precisely and the classification is elaborative with precise measurement excluding any chance of confusion during categorization. It is described that skeletal maturity assessment using MP3 radiographs was found to be simple, highly reliable, and less expensive and could be conveniently used as a simple diagnostic tool by all dental practitioners for an effective treatment planning. ${ }^{13}$ Similar findings were reported using digital MP3 radiographs. ${ }^{17}$ The stages were categorized into pre-peak, peak, and post-peak for comparing it with other types of skeletal maturation.

Similar categorization was done to compare both the classifications in the present study. However, no comprehensive study has been reported on the actual measurements of epiphysis and diaphysis to evaluate skeletal maturity and hence the present study becomes the pioneer one. The present study was designed to propose a new classification (using digital measurements) that is simple, precise, reliable, and can be easily utilized and reproduced whenever required. It was also designed to estimate reliability and validation of the new classification based on a formula for quantifying skeletal maturation by determining a correlation between epiphysis and diaphysis of middle phalanx of the third finger.

Pedodontist may encounter many abnormal conditions in a growing child that need intervention. The age group selected in this study was kept wide in order to cover entire stages of maturation. As interceptive orthodontic treatment may be required in any age group, skeletal age assessment becomes most critical in diagnosis and treatment planning. ${ }^{26}$ The study was of a double-blind type, in which all investigators measured the amount of growth based on the percentage of epiphyseal development derived from the formula and categorized them.

There was less accuracy or agreement in the old classification by nonpedodontists who did not have a thorough knowledge. However, it was seen that there was $90 \%$ agreement among them in the RMS-MP3 classification. Similarly, pedodontists showed better agreement among themselves in evaluating the skeletal maturity in RMS-MP3 classification. These differences may be due to the assumptions done especially while using old classification.

It was seen that there was $89 \%$ of agreement in the RMS-MP3 classification among all the four observers (including pedodontists and nonpedodontists) when compared to $38 \%$ of agreement in the old classification, indicating the new classification to be far superior to the old one.

The RMS-MP3 classification appears to be simple, easy, and accurate, eliminating disadvantages of older classification system with the advantage of ease of monitoring of growth with measurements using a digitalized technique. The results of the present study showed that there was a significant difference in categorization using different classifications with newly proposed RMS-MP3 classification presenting minimal difference. The new classification could be used by anyone (no expertise required) and can be used reliably for assessing the skeletal maturity.

A precise evaluation of maturational stages should be an integral part of both diagnosis and treatment planning. There are numerous methods reported in the literature by different authors 
in an attempt to determine the best indicator of maturity. Every method has its own advantages, disadvantages, and limitation over the other method. But still studies are being conducted to explore the best method to assess the maturity of an individual. ${ }^{27}$ However further studies on larger samples with many observers need to be carried out to accept or reject the hypothesis regarding the newly proposed RMS-MP3 classification.

\section{CONCLUSION}

The assessment of growth is of utmost importance in planning of orthodontic and myofunctional treatment. The newly proposed RMS-MP3 classification can be an alternative and perfect aid in assessing growth with accuracy, precision, ease, and an increased reliability.

\section{References}

1. Grave KC, Brown T. Skeletal ossification and the adolescent growth spurt. Am J Orthod 1976 June;69(6):611-619. DOI: 10.1016/00029416(76)90143-3.

2. Todd TW. Atlas of skeletal maturation: Part 1, The hand. St Louis: Moseby and Co.; 1937.

3. Greulich WW, Pyle SI. Radiographic atlas of skeletal development of the hand and wrist. 2nd ed., California: Stanford University Press; 1959.

4. Lamparski DJ. Skeletal age assessment utilizing cervical vertebrae [master of dental science thesis], 2nd ed. Pittsburgh: University of Pittsburgh, School of Dental Medicine; 1972.

5. Grave K, Townsend G. Cervical vertebra maturation as a predictor of the adolescent growth spurt. Aust Orthod J 2003 April;19(1): 25-32.

6. Tanner JM, Whitehouse $\mathrm{RH}$, et al. The adolescent growth spurt of boys and girls of the Harpenden growth study. Ann Hum Biol 1976 Mar;3(2):109-126. DOI: 10.1080/03014467600001231.

7. Patil AA, Revankar AV. Reliability of the frontal sinus index as a maturity indicator. Indian J Dent Res 2013 July-Aug;24(4):523-527. DOI: 10.4103/0970-9290.118372.

8. Demisch A, Wartmann P. Calcification of the mandibular third molar and its relation to skeletal and chronological age in children. Child Dev 1956 Dec;27(4):459-473. DOI: 10.2307/1125899.

9. Hagg U, Taranger J. Maturation indicators and pubertal growth spurt. Am J Orthod 1982 Oct;82(4):299-309. DOI: 10.1016/00029416(82)90464-X.

10. Uysal T, Sari Z, et al. Relationships between dental and skeletal maturity in Turkish subjects. Angle Orthod 2004 Oct;74(5):657-664.

11. Abdel-Kader HM. The reliability of dental X-ray film in assessment of MP3 stages of the pubertal growth spurt. Am J Orthod Dentofacial Orthop 1998 Oct;114(4):427-429. DOI: 10.1016/S08895406(98)70188-X.
12. Rajagopal R, Kansal S. A comparison of modified MP3 stages and the cervical vertebrae as growth indicators. J Clin Orthod 2002 Jul;36(7):398-406.

13. Madhu S, Hegde AM, et al. The developmental stages of the middle phalanx of the third finger (MP3): A sole indicator in assessing the skeletal maturity. J Clin Pediatr Dent 2003 Winter;27(2):149-156. DOI: 10.17796/jcpd.27.2.qtj75rg3714l5543.

14. Ozer T, Kama JD, et al. A practical method for determining pubertal growth spurt. Am J Orthod Dentofacial Orthop 2006 Aug;130(2):131e1-131e6. DOI: 10.1016/j.ajodo.2006.01.019.

15. Hagg U, Taranger J. Skeletal stages of hand and wrist as indicators of the pubertal growth spurt. Acta Odontol Scand 1980;38(3):187-200. DOI: $10.3109 / 00016358009004719$.

16. Leite RH, O'Reilly MT, et al. Skeletal age assessment using the first, second and third fingers of the hand. Am J Orthod Dentofacial Orthop 1987 Dec;92(6):492-498. DOI: 10.1016/0889-5406(87)90231-9.

17. Hegde DY, Baliga $S$, et al. Digital radiograph of the middle phalanx of the third finger (MP3) region as a tool for skeletal maturity assessment. Indian J Dent Res 2012 Jul-Aug;23(4):447-453. DOI: 10.4103/0970-9290.104947.

18. Mayoral J, Mayoral G. Orthodontics: Fundamental principles and practice, 6th ed. Barcelona, Spain: Labor SA; 1990.

19. Gutierrez Muniz JA, Berdasc Gomez A, et al. Crecimiento y Desarrollo. En: Colectivo de Autores. Pediatría. T1. [en línea]. La Habana: Editorial Ciencias Médicas; 2006; pp. 27-58.

20. Baccetti $T$, Franchi $L$, et al. The diagnostic performance of chronologic age in the assessment of skeletal maturity. Prog Orthod 2006 Nov;7(2):176-188.

21. Bhanat S, Patel D. Dental and skeletal maturity indicators of chronological age: Radiographic evaluation amongst children in Gujarat, India. IOSR J Dent Med Sci 2013 May-Jun;6(4):6-12. DOI: 10.9790/0853-0640612.

22. Baccetti T, McGill JS, et al. Skeletal effects of early treatment of Class III malocclusion with maxillary expansion and face-mask therapy. Am J Orthod Dentofacial Orthop 1998 Mar;113(3):333-343. DOI: 10.1016/ S0889-5406(98)70306-3.

23. Franchi L, Baccetti T, et al. Shape-coordinate analysis of skeletal changes induced by rapid maxillary expansion and facial mask therapy. Am J Orthod Dentofacial Orthop 1998 Oct;114(4):418-426. DOI: $10.1016 /$ S0889-5406(98)70187-8.

24. Enlow D, Hans M. Essentials of facial growth. Philadelphia: W.B. Saunders; 1996; pp. 65-72.

25. Mayarí GT, Lugo RO. A simplified method to determine the potential growth in orthodontics patients. Rev Cubana Estomatol 2010 Apr-Jun; 47(2):134-142.

26. Negi KS, Sharma VP, et al. Assessment of growth impetus using MP3 maturation and its correlation with CVMI and dental age. J Ind Orthod Soc 2003 Oct-Dec;36(4):204-213.

27. Dhiman $S$, Maheshwari $S$, et al. Assessment of maturity in orthodontics: A review. J Adv Clin Res Insights 2015 Mar-Apr;2(2): 100-103. DOI: 10.15713/ins.jcri.54. 